\title{
1. Economic theory of non-territorial unbundling
}

Imagine buying cars the way we buy governments. Ten thousand people would get together and agree to vote, each for the car he preferred. Whichever car won, each of the ten thousand would have to buy it. It would not pay any of us to make any serious effort to find out which car was best; whatever I decide, my car is being picked for me by other members of the group. Under such institutions, the quality of cars would quickly decline.

David D. Friedman, The Machinery of Freedom

\section{THE POLITICAL CHOICE PROBLEM: A BETTER WAY?}

Much has been said about the vices and virtues of democracy. Democracy, said Benjamin Franklin, is two wolves and a sheep voting on what to have for dinner. ${ }^{1}$ Lord Acton warned that democracy is susceptible to a 'tyranny of the majority'. ${ }^{2}$ Winston Churchill told us that democracy is actually the worst form of government ... except for every other form that has been tried. Not without irony, he also said that the best argument against democracy is a five-minute conversation with the average voter. ${ }^{3} \mathrm{H}$. L. Mencken described democracy as the theory that people know what they want, and deserve to get it good and hard. ${ }^{4}$

These quotes speak to the majoritarian dimension of democracy and the reality that even in the best-of-functioning systems 49 per cent of the people can remain unhappy. To be sure, in most modern democracies even a less-than-majority popular vote can carry an election, due to the peculiarities of electoral systems. ${ }^{5}$ Democracy, in other words, is a system to ensure that some people get what they want; it is not a system to allow everyone to do so.

From a purely economic perspective, the purpose of government is to administer collective goods that would otherwise fail to be provided and to help overcome coordination problems on population-wide, mutually preferred economic outcomes. Governance amounts to a sort of collective goods provision problem; majoritarian democracy is a social technology we use to all choose the same set of collective goods and institutions that harms the least number of people. 
But is this the best we can do? Isn't this definition of successful governance a little shallow? We are still struck with the reality that swaths of the population remain unhappy with a set of collective goods and government that they did not choose and are effectively forced to consume, with little to no recourse for satisfaction. A truly efficient system of governance, on the other hand, is one in which citizens are able to relate their preferences over policies in a more detailed and filigreed way. ${ }^{6}$ The challenge then is to find a system we can use to all choose different sets of public goods and institutions that please the most number of people, in contradistinction to governance as we know it.

The traditional approach to this challenge is to territorially decentralise and provide differentiated bundles of collective goods and services at the regional or local government levels. ${ }^{7}$ This has proved more or less successful throughout history and across the world, but the territorial sorting mechanism on which it is based is subject to inherent efficiency limitations. In short, if people sort themselves over territorial jurisdictions according to their political preferences, they must sacrifice economic and social spatial preferences, thereby limiting efficiencies in these other realms. The same applies in reverse, and in most cases we simply decide where to live based on economic and social considerations, at the expense of efficiency in political choice. ${ }^{8}$

Moreover, the benefits of decentralisation have nothing to do with the inherent territoriality of regional or local governments, but rather they follow from mechanisms underlying decentralised, parallel governance, and equally apply to a non-territorial system of governance. The solution to the limits of territorial decentralisation, then, is rather obvious: non-territorial decentralisation.

The governance problem is about political choice; and there are two related features of political choice that contribute to this challenge. The first might be termed the majoritarian problem; that is to say, no matter what you would choose, you get what everybody else chooses. This is cause for much disagreement between people, as politicians and advocates (as well as the general population, though often unwittingly) manoeuvre to impose their conceptions of "what government ought to do' for society at large. ${ }^{9}$ Political choice has degenerated into an electioneering numbers game, and more often we are simply lumped with a choice between bundles of government policies that the median voter might have chosen. ${ }^{10}$

This point is not lost on the wider public, and as a result the majoritarian institutional feature is not particularly amenable to informed political choice on the part of the citizen, and nor does it elucidate much information about citizens' political preferences on the part of government. 
The second feature of political choice as we know it might be termed the bundling problem; that is to say, when you choose, you have to choose everything all at once. This, too, is cause for much disagreement-but within people - who, even supposing they aren't prey to the majoritarian problem, are unable to reconcile the internal incompatibilities of preformed government bundles offered by rival political parties. ${ }^{11}$ To put another way, bundled governance generates innate political preference incongruities (i.e. trade-offs) and impedes preference satisfaction over the full suite of government policy areas. ${ }^{12}$

Again, the wider community understands this frustration - particularly younger generations, who find neither Conservative nor Liberal nor Social Democrat policy-bundle offerings altogether appealing - a likely explanation for the concurrent, though seemingly contradictory, political disaffection at the party-platform level and often viral enthusiasm for advocacy campaigns at the single-issue level. And again, the bundling institutional feature stifles political choice and suppresses information about citizens' political preferences.

We can overcome the majoritarian problem and the bundling problem, as well as the inherent geospatial trade-offs in territorial decentralisation, by carrying the decentralisation ethos to its logical ends: unbundle as many functions of government as possible (whether territorial or not), decentralise non-territorially where feasible, and promote parallel governance. The reality is we don't need to all agree on the same set of collective goods and institutions. By 'unbundling governance' we can each individually choose the public goods and services that we want and rebundle them as we like.

What might such an approach look like? Proposals of this kind are essentially variations on the 'voting with one's feet' political sorting mechanism and theories of competitive governance. ${ }^{13}$ In the first instance these are familiar ideas such as competitive federalism, fiscal decentralisation, devolution, autonomous regions, and other territorial expressions of the voting with one's feet principle like special economic zones, charter cities and seasteading. ${ }^{14}$ But equally so, the standard applies to methods of non-territorial decentralisation such as market decentralisation (i.e. privatisation and private governance),${ }^{15}$ multi-level governance, ${ }^{16}$ polycentric governance and functional, overlapping and competing jurisdictions, ${ }^{17}$ parallel governance and autonomous spaces, ${ }^{18}$ non-territorial consociation (typically for geographically dispersed minorities), ${ }^{19}$ non-territorial and national-cultural autonomy, ${ }^{20}$ millet and extraterritorial jurisdictions, ${ }^{21}$ the political philosophy of panarchism, ${ }^{22}$ or even Robert Nozick's 'utopia of utopias', ${ }^{23}$ among other non-territorial possibilities. ${ }^{24}$ All of these theories and mechanisms, whether territorial or non-territorial, can be subsumed under the concept of 'unbundled governance'. 


\section{THE TRADITIONAL SOLUTION: TERRITORIAL DECENTRALISATION}

Traditional solutions to these problems are variations on the theme of competitive governance; that is, political decentralisation and competitive federalism. The idea is that a simple territorial division into regional or even local jurisdictions (i.e. bundles of government) allows people to sort themselves into the government that best represents their political preferences; this is the voting with one's feet mechanism.

By doing so the majoritarian problem is somewhat lessened: citizens have stronger voice in a federal majoritarian system than in a unitary majoritarian system (the smaller the political unit, the greater the individual political influence and the more valuable the citizen's vote); and even if they still fall prey to the tyranny of the majority, they have recourse to exit. This also reduces the bundling problem: decentralisation is a form of unbundling, as a portion of government policy areas are removed from the central government and reassigned to subsidiary political units (i.e. rebundled, but in smaller bundles); so in principle citizens are afforded greater choice and, from the perspective of the citizen, there may be less political preference incongruity within the smaller bundles on offer at each level.

Notice, however, that these are only partial solutions to the majoritarian and bundling problems; they are weakened but not eliminated. The potential for tyranny of the majority still exists for the citizen of a relatively decentralised jurisdiction; and the citizen is still made to choose between preformed government bundles, albeit smaller ones. Taking the competitive governance argument to its logical ends, the majoritarian and bundling problems will only be eliminated in a system of governance with either a sufficiently large number of jurisdictions with sufficiently diverse policy-bundle offerings, or in a fully unbundled system in which the citizen is free to 'curate their own state'.

We will come back to this point, but for now note that better political choice and more competition can be achieved in two ways: (1) raising the benefits of switching governments by devolving control over more policy areas to lower-level political units, thereby generating conditions for greater variety in the government bundles on offer; or (2) lowering the costs of switching by making jurisdictions smaller and easier to move between.

By doing the above, the benefits of changing government are more likely to outweigh the costs of actually having to move between jurisdictions, and people will be able to enjoy the benefits of variety in government without having to sacrifice other economic or social preferences. People may be unwilling to move from Melbourne to Brisbane in search of their preferred 
political bundle, but many are willing to move across neighbourhoods (such as from Melbourne to Parkdale); they can still live near to their friends and community, they can still visit their favourite restaurants and travel easily to and from work, and so on.

These institutional features generate a political choice setting that begins to resemble a competitive market; so we should expect greater incentives for citizens to inform themselves of political options and more information to be revealed about citizens' political preferences. Indeed, the underlying voting with one's feet concept was originally envisioned as a quasi-market mechanism:

Just as the consumer may be visualised as walking to a private market place to buy his goods, the prices of which are set, we place him in the position of walking to a community where the prices (taxes) of community services are set. Both trips take the consumer to market. There is no way in which the consumer can avoid revealing his preferences in a spatial economy. Spatial mobility provides the local public-goods counterpart to the private market's shopping trip. ${ }^{25}$

Moreover, by voting with one's feet citizens not only sort themselves optimally into the jurisdictions offering their preferred bundles of taxes and public services, but they also incentivise the political units to compete for their membership, assuring that the public goods demanded will be provided at the lowest cost. This capacity to limit oversupply and overtaxation that is characteristic of monolithic, central government- to 'tame the Leviathan'-is one of the foremost virtues of the decentralised institutional form. Further, the lobbying advantages that special interests hold over the general public - the balance of concentrated benefits and dispersed costs, as Mancur Olson explained - are eroded as political unit size decreases. The impacts of government failure are also tempered since policy mistakes have smaller consequences and policy successes can be replicated. In this sense, political decentralisation can be considered a kind of 'meta-solution' to the problems of concentrated power and government failure in monocentric political systems.

Most importantly, competition serves as a discovery process. ${ }^{26}$ Since the risks associated with innovation are less for sub-national governments, they will, other things being equal, have a greater propensity to innovate. ${ }^{27}$ The political system as a whole is characterised by parallel experimentation (i.e. multiple policies are tested simultaneously by competing sub-national governments) rather than serial experimentation (i.e. multiple policies can only be tested singly by a central government). From an evolutionary perspective, political-jurisdictional competition can be compared to the process of natural selection; parallel experimentation and migration of discoveries between constituent political 'laboratories' is key. ${ }^{28}$ 
Decentralisation therefore provides a framework for experimentation and learning about policy alternatives and their consequences, and the system as a whole incorporates - and discovers - far greater amounts of information than a more centralised, monolithic public service complex. ${ }^{29}$ All-inall, market-like competitive constraints provide structural limitations on government power while promoting the advantages of competition and innovation in governance.

\section{THE EFFICIENCY LIMITS OF TERRITORIAL POLITICAL SORTING}

However, the decisive point alluded to in the passage by Charles Tiebout above is not that of benefits, but costs: the adjustment process has inherent efficiency limits due to mobility costs. When we talk about voting with one's feet we invariably refer to a spatial phenomenon; notions of competitive federalism, political decentralisation and in vogue 'big ideas' like special economic zones, charter cities, and seasteading, are all territorial expressions of the sorting principle. The major limitation of the voting with one's feet proposition, at least in its idealised form, is that it relies on perfect mobility between jurisdictions (i.e. costless moving), yet sorting over territorial jurisdictions is inherently costly and never perfect.

Do you know anyone who has changed cities to better fulfil their political preferences? What if you are unwilling to move even from Melbourne to Parkdale? The effectiveness of competition among political jurisdictions is inversely proportional to the costs of changing jurisdiction; simply converging on ever-smaller territorial units might reduce switching costs, but this can never be complete. This is because people also make locational decisions based on private and social activities - career, friends and family, restaurants, recreation, the great outdoors, and so on. There might not be much overlap between the people you want to live with and the people who would choose the same form of government as you; in effect, we put up with government we don't like in order to live near the people and places we do.

A complex of many small local governments - even if for the sake of argument we concede costless moving-promotes mobility away from economically and socially optimal locations. Sorting thus generates incentives for people to move away from where they would have located if public goods and services were provided non-territorially. Territorial political sorting therefore causes deadweight loss and reduces what is termed 'agglomerative' efficiency. On the other hand, economic and social agglomerative efficiency dictates that citizens sort for reasons other 
than their political preferences, which causes a reduction in the efficiency of political sorting. ${ }^{30}$ Again, this efficiency limit exists relative to an alternative system of non-territorial political jurisdictions.

To the extent that public, private and social preferences over geographical space are non-identical, there exist structural efficiency limits of territorial political sorting. And the more that political preferences diverge from other geospatial preferences, the more preferable non-territorial governance becomes to political territoriality.

\section{THE NON-TERRITORIAL SOLUTION}

Unless preferences for neighbours and policies coincide, citizens face a trade-off in a world of territorial governance. Of course, trade-offs are an inescapable reality in economic life; but since we are interested in solving the political choice problem, we should ask: is there another way? Fortunately, there is another solution: non-territorial decentralisation. Just as a nation can be divided into many small geographically distinct territories for purposes of local and regional government and national representation, so too can it be divided into analogous non-territorial political units. ${ }^{31}$

The idea of non-territorial governance might sound strange at first, but if we think of governance as just another industry, it makes sense. ${ }^{32}$ For instance, we choose our mobile phone provider, our health insurance provider, our superannuation provider, and so on, all irrespective of location. If switching costs are all that stand in the way of an efficient, political preference satisfying allocation of collective goods and services-costs that directly follow from an explicitly territorial mode of political organisation - then it seems forthright to suggest a decoupling of political jurisdiction and geographical location so that people could switch political jurisdictions without switching location.

In a world of non-territorial governance people would be able to change their political affiliations, in effect memberships or subscriptions to club-like governance providers, as easily as one changes health insurance providers, without ever having to change location. Non-territorial governments would be defined by their memberships of citizen-consumers (more or less of whom may happen to reside in a given territory) and not necessarily the territory itself. In such a system, governance doesn't follow the territory, but rather the person.

People with different values, beliefs and political preferences could 'migrate in place' to different non-territorial states. We would likely see a proliferation of heterogeneous political bundles: different states may offer 
varying levels of services in areas such as health, education and unemployment insurance, for different prices. The particulars of the states that might emerge are difficult to comprehend ahead of time; conceivably, they could span the entire ideological spectrum, although we should expect them to broadly reflect already-existing political preferences, and would therefore offer relatively familiar policy bundles to those that we are faced with today. The difference, however, is that jurisdictions will be extended nonterritorially, so that you and your next-door neighbour might be citizens of quite different governments:

Suppose that at the beginning of the year, you sign up for your preferred national government. You enroll yourself for one year. Next year you may make a different choice. To keep matters simple, suppose that you have three choices: Republican (Red), Democrat (Blue), and Libertarian (Coral). But in the back of your minds, understand that there can be more choices. There can be Green, Red Lite, Blue Lite, Yellow, and so on. If you choose Red, you agree to abide by Red's national government. If you choose Blue or Coral, you agree to abide by their national governments, respectively. You may choose Red and your neighbour may choose Coral. Each of you decides to abide by your own selected national governments. The Reds, Blues, and Corals live all over the place in crazy-quilt patterns. ${ }^{33}$

The underlying logic of the voting with one's feet mechanism is directly applicable to a decentralised system of non-territorial states; it is perfectly general and applies to territorial local government jurisdictions, nonterritorial jurisdictions, and private goods alike (indeed, it mimics consumer choice theory). In fact, non-territorial governance more accurately resembles the political quasi-market, in which political firms (i.e. territorial public enterprises) compete over citizen-consumers, that was originally envisioned of the sorting mechanism. Indeed, James M. Buchanan noted, 'Tiebout's analysis may best be interpreted as an early and pioneering attempt to describe the adjustment process in an essentially nonspatial world of voluntary clubs' ${ }^{34}$

Decentralisation is principally a non-territorial phenomenon, albeit one that has been applied up until now primarily in a territorial context. The key insight is that welfare is maximised when collective goods and services are provided by political units to subsets of the population with homogeneous political preferences. This means decentralisation of some sort; for some time ever-smaller territorial units have been the means to achieving this, but we should pursue non-territorial decentralisation too.

In such a world of non-territorial federalism, all the competitive and innovative benefits of quasi-market competition are heightened: collective goods and services would be provided more efficiently and the amount of state interference that people would tolerate without switching would be 
lower (the Leviathan would be not only tamed, but domesticated); states would compete on innovation and service as well as price (or more accurately, rather than being shielded from competition by regional monopoly and mobility thresholds), and would need to tailor their suite of services to meet citizens' political preferences; special interest lobbying would be greatly restricted if not altogether futile given the ease of exit from captured jurisdictions; and importantly, non-territorial governance promotes a superior distribution of people over geographic space, and citizens are free to locate according to their own interests - political preferences need no longer conflict with economic and social preferences.

\section{THE UNBUNDLED SOLUTION}

Next we should consider the bundling problem. Non-territoriality doesn't deal with this; it is a way of overcoming the limitations of territorial sorting while generating more diversity in government policy bundles. But what if, even in a non-territorially decentralised system, the bundle of collective goods and services that best satisfies your political preferences is not offered? Political preferences over distinct functions of governance are often mutually exclusive, at odds with each other, or simply not offered coextensively by governments or rival political parties. That is, the nature of the modern nation-state as a general-purpose form of political organisation generates innate political preference trade-offs within the individual, not only between individuals, and impedes preference satisfaction over the full suite of governance functions. Put another way: many people begrudge how pay TV companies bundle their packages of services-why don't we have that same resentment over government bundling? ${ }^{35}$

Consider the possibility of unbundled governance, where independent single-purpose governments or public enterprises that are functionally specialised provide collective goods and services separately. This is 'government à la carte': there will be greater diversity of governmental forms and a wider range of choice for groups and individuals. More to the point, citizens will be able to personally curate the suite of collective goods and services that is amenable to their unique political preferences; they are free to opt in to the ones that suit their values, in effect rebundling the functions that have been deemed 'unbundleable'.

Even if there are relatively few unbundleable governance functions, and even if there are relatively few public enterprises from which to choose, the welfare gains from improved political preference satisfaction under such a system could be substantial. Indeed, only when citizens' choices converge on what would be the fully bundled, majoritarian-democratic result will 
welfare gains be trivial (i.e. when there is near-unanimity; an outcome of vanishingly small probability). ${ }^{36}$ When citizens are able to assemble their own political bundles based on their unique preferences, the stifling effect of 'one-size-fits-all' political monopolism and the internal contradictions in preformed political bundles are diminished; frustration is replaced by customisation.

Just as a monolithic, general-purpose corporation is not the solution to all private enterprise problems, a monolithic, general-purpose government is not the solution to all public enterprise problems. Rather, competing public enterprises should be free to provide these same services, so that citizens can choose among a range of options and select the providers most responsive to their political preferences. Think of this as 'government by subscription' or the freedom to 'curate your own state'. This is not to say that existing governments should be abolished, nor that all services that governments have traditionally provided should be opened up to other providers; simply that the monopolistic and general-purpose features of government should be questioned if we desire a system that satisfies citizens' political preferences. Citizens who wish to remain subject to a relatively hierarchical, consolidated public enterprise would be free to do so; but equally, citizens wishing to opt in to other arrangements would be free to do so as well.

The key point in relation to the bundling problem and decentralisation is that the subsets of the population for which political preferences are homogeneous differ on a function-by-function basis. So not only is it unlikely that the people you prefer to live nearby will have similar political preferences over the whole suite of public goods and services, but for each distinct function of governance there will be a different community of interest that shares that particular political preference with you.

Furthermore, the diversity of scale economies, spillovers, and externalities for different collective goods and services means that each citizen should be a member of numerous multi-scaled, overlapping jurisdictions. For some collective goods, the optimal jurisdiction size is the entire country, for others it is narrower. But if the optimal jurisdiction size depends on the specific collective good or service, then everyone should belong to multiple overlapping jurisdictions: one for each function of government. ${ }^{37}$

Collective goods and services that happen to have coterminous jurisdictional boundaries or membership bases could be bundled, but if this insight were to be applied strictly, it seems more likely that some amount of unbundling would in fact be called for. Bruno Frey suggests that each individual would belong to a different group each for cultural affairs, transportation, schooling, social security, healthcare, telecommunications, and so on; labelling the result 'functional federalism'. 
Moreover, recall the principle virtues of decentralisation are adaptiveness to citizen preferences (due to 'localness' or 'closeness') and greater efficiency in provision (from knowledge of costs and benefits of production). There is reason to believe that a decentralised regime of jurisdictions defined predominantly by function rather than geography will be at least as responsive to citizen preferences (as jurisdictions become smaller), and indeed, more attuned to the specifics of production (as jurisdictions become functionally specialised) - thus ensuring even greater efficiency and welfare.

Of course, greater satisfaction with political preferences does not come for free, and there are potentially increased coordination costs, spillovers, information costs and decision burden associated with a conceptually fully unbundled system of governance. The point for now, however, is to highlight this very trade-off - that alternative political systems can indeed result in greater citizen satisfaction, albeit at some cost - while calling into question the presumption of monopolistic, bundled governance.

\section{UNBUNDLE, ONLY TO REBUNDLE?}

We should unbundle the functions of government and provide them distinctly according to their diversity. Each type of government activity has slightly different externalities or economies of scale from the others and therefore requires a different size (i.e. in terms of a territorial jurisdiction or non-territorial membership base). This is expressed in Mancur Olson's notion of 'fiscal equivalence': for every collective good, there is a unique boundary for which a separate government is needed, so that 'there can be a match between those who receive the benefits of a collective good and those who pay for it'. ${ }^{38}$ Thus we should observe a complex of overlapping jurisdictions with unique boundaries relating to the provision of specific collective goods. In the case of non-territorial jurisdictions, the boundaries for fiscal equivalence would be defined not as territorial borders but personal associations. As Olson suggested, 'There is a case for every type of institution from the international organization to the smallest local government'; a case for 'both centralized and decentralized units of government in the same context'. ${ }^{39}$

One might add that there is similarly a case for a great many more institutional forms in the same context. We can have centralisation and decentralisation, we can have bundling and unbundling, we can have territorial provision and non-territorial provision - but we need a framework in which the assignment of powers can be discovered, and continually rediscovered, not assumed a priori. This is a framework for an unbundled 
state, but it might be more accurately described as an 'unbundleable' state. Where possible, we should allow political entrepreneurs to unbundle the functions of government by creating parallel entities for the provision of a particular collective good or service. This would require free-in the sense of being unrestricted, not costless - entry of new public enterprises and emergence of new jurisdictions.

Territorial and non-territorial decentralisation are the mechanisms by which this might happen. The political entrepreneur may wish to create a territorial public enterprise if economic logic dictates that production, provision or consumption of the collective good or service need be local. Conversely, there may be scope for the creation of non-territorial government units. Both acts require in the first instance the unbundling of governance and the creation of a new, parallel public enterprise, whether territorial or non-territorial.

While unbundling is key to this, the point is not to rule out all bundling of functions of government - as mentioned, unbundled jurisdictions that happen to have coterminous boundaries or membership bases could be rebundled. Rather the point is to create an unbundleable system of governance and allow this decentralised system to discover ways to rebundle functions; the role of the political entrepreneur is to discover scales and scopes of public service production and provision.

Public enterprises may decide to jointly provide a suite of goods or services should they discover coterminous economies of scale or scope; or even without such economies, purely as a marketing exercise (although presumably this would be based on some underlying economy). Similarly, where separate public enterprises are able to derive an advantage through the formation of a new joint enterprise for an encompassing larger community there would be recourse to form yet another larger self-governing public enterprise. This might involve smaller public enterprises, working within the same domain but serving different communities, coordinating to serve a larger joint membership; or it might involve functionally distinct entities cooperating to provide a suite of services to a common membership.

The theory of unbundling government is therefore best explicated in terms of discovery frontiers: promotion of parallel experimentation to generate knowledge of the proper extent of territoriality and bundledness in the prevailing complex of jurisdictions and public enterprises. The public service industry would be characterised by both single-function public enterprises and multi-organisational arrangements in response to diverse economies of scale and the demands of varying communities of interest. Some of the single-function enterprises would service non-territorially defined membership bases, while others would be restricted by geography; similarly so for bundled arrangements, with the possible addition of hybrid 
bundles that comprise both territorial and non-territorial provisions of governance. Concurrent, non-centralised authority will exist simultaneously in a larger industrial complex of overlapping jurisdictions of public enterprises.

\section{ECONOMIES OF SCALE AND SPILLOVER EXTERNALITIES}

An important form of cooperation between public enterprises one would expect to emerge is purchasing agreements. These are already used by lower-level jurisdictions in territorially decentralised systems of governance; for example, often larger local governments produce their own police services while smaller governments purchase their services by hiring from the larger government or national government. This is a way of dealing with diverse economies of scale in such a way as to capture diminishing supply costs (i.e. when the efficient scale of production is relatively large) while maintaining inter-jurisdictional competition (i.e. having more than a single public enterprise perform the function). In a similar fashion, national governments sometimes perform administrative functions as a means of alleviating insufficient economies of scale of smaller sub-national governments (e.g. tax collection).

We need not assume that a particular government unit must provide its own facilities or produce a particular collective good or service. This dissociates the efficient scale of production from the efficient scale of provision or consumption. That is, if a public enterprise can purchase from a specialised producer, then the economies of scale cease to have relevance to the size of the governmental unit, and we can have multiple overlapping, competing enterprises servicing a given territorial space. And public enterprises would still be free to create higher-level consortiums that adopt a common policy or provision of some particular good, given that the constituent enterprises represent the preferences of their members in doing so.

However, the very act of decentralisation may cause inter-jurisdictional spillovers of both benefits and costs: if you have a very large number of public enterprises and overlapping jurisdictions presumably there will be externalities generated by individual units on each other. Therefore, the public enterprise chosen to deal with any given activity should be large enough to internalise any externalities that the activity generates (or some arbitrary proportion of the externalities, since border spillovers are pervasive). ${ }^{40}$ Again, according to this criterion each function of government or collective good calls for a different size public enterprise due to the 
diversity of externalities. And again, this would seem to be reason for everlarger jurisdictions, as a means of internalising an ever-larger proportion of externalities.

If we want to maintain the benefits of inter-jurisdictional competition and parallel governance then the decentralised public enterprises will need to coordinate to internalise spillovers, but coordination is costly. Externalities can be internalised through voluntary policy coordination among interacting public enterprises; or a new level of organisation can be created to deal with externalities. For instance, this might require the creation of a public service enterprise with the specific task of internalising the externalities generated by the individual enterprises on each other, through tax and subsidy transfers.

These new government units would perform a role similar to that of a central government (i.e. stabilisation and distributive objectives), although there would likely be a multitude of such new enterprises, specialised according to the coordinative function they perform. However, if the externalities of a particular collective good or service are sufficiently widespread (and coordination costs are intolerably high), a higher-level enterprise may have to assume complete responsibility for its provision. Thus, there seems to exist an inherent trade-off between the advantages of decentralised parallel governance (coupled with coordinated internalisation of externalities) and the disadvantages of centralised governance (with less need for costly coordination activities).

Again, the first point is to highlight this very trade-off: in the final comparative analysis decentralised parallel governance may in fact trump presumptive centralisation. And in the second instance, we should consider the role of political entrepreneurship and parallel experimentation in the discovery of dynamically efficient jurisdictional systems. ${ }^{41}$ It may very well be the case that a complex of overlapping public enterprises is statically inefficient in terms of generating inter-jurisdictional spillovers. Yet the very same complex design might cultivate a superior policylearning environment, precisely because the presence of externalities creates opportunity for political entrepreneurial behaviour. ${ }^{42}$ In this sense, a statically inefficient complex of jurisdictions and public enterprises is in fact dynamically efficient and therefore preferable to spillover minimising centralisation. David Ellerman makes the argument in this way: 'parallel experimentation is a fundamental dynamic efficiency scheme to enhance and accelerate variation, innovation, and learning in contexts of genuine uncertainty or known ignorance'. ${ }^{43}$ Put another way, a centralised system of governance devoid of parallel experiments is likely to be dynamically inefficient and generate a comparatively larger externality problem. 


\section{COMPLEXITY OF CHOICES}

Central to this proposal is the argument that a truly efficient system of governance is one in which citizens are able to relate their preferences over policies in a more detailed and filigreed way. In addition to this image of statically efficient political preference satisfaction, is the prospect of dynamic efficiency: non-territorial unbundling cultivates entrepreneurial discovery of the extent of territoriality and bundledness necessary for preference satisfaction, and promotes continual experimentation and rediscovery. We should, however, expect there to be some complexity or cognitive constraints to all this, well inside the extreme of having each and every aspect of government unbundled and provided by autonomous public enterprises.

We have already seen how scale economies and the need to internalise externalities can sometimes temper the arguments for unbundling; but the most straightforward rationale for bundling (or, granted, rebundling) is that the innumerable combinations of government bundles imposes onerous information costs on the citizen-chooser-not to mention on public enterprises that are expected to provide as wide a range of choice of combinations as possible. The educational level and informational costs required to take advantage of the opportunities inherent in such a system would largely be burdensome, and the likelihood of a citizen actually sorting over the space of possible bundles to find their optimum - should a perfectly complete governance marketplace be imagined — is vanishingly small.

Yet if the complexity of a fully unbundled system is incomprehensible to the mere citizen-chooser and hence unnavigable, then the correlate argument must be that the complex combinatorics of an unbundleable system is incomprehensible to the mere jurisdictional designer and hence unplannable. For the question of the bundledness and territoriality of jurisdictional design this is an important counterpoise. Just as public choice theorists demand behavioural symmetry between self-interested economic agents and public officials, ${ }^{44}$ and robust political economy calls for comparative institutional analyses under symmetrical deviations from ideal assumptions about motivation and information (e.g. 'limited benevolence' and 'limited rationality'), ${ }^{45}$ so too must we approach comparative analyses of relatively more-or-less bundled and territorial modes of political organisation (and complexity and cognitive difficulties therein) with symmetry between citizen-chooser and would-be jurisdictional designer.

The task of the jurisdictional designer is analogous to that of the central planner charged with determining the welfare maximising allocation of resources in an economy. While beginning in the 1920s it was Ludwig von 
Mises and Friedrich Hayek who were the primary opponents of market socialist economic planning, ${ }^{46}$ already a decade earlier Vilfredo Pareto had provided a 'computational complexity' critique of his own. ${ }^{47}$ According to Pareto, calculation of equilibrium conditions is 'an absurd hypothesis' with no 'practical possibility of solving the problem'. ${ }^{48}$ This is because with only a small number of individuals and goods the system of equilibrium conditions would far exceed the capacity of algebraic analysis. Therefore, he insisted, 'the only means of solving them would be to observe the actual solution which the market gives' ${ }^{49}$

Similar critiques can be mounted against the hypothesis that a welfare maximising jurisdictional design (i.e. an allocation of people to jurisdictions) can be planned for by solving the system of inter-jurisdictional externality optimality conditions. Just as an economy cannot be seen as a set of equations, neither can the jurisdictional design of a polity be reduced to rational construction: it is impossible to calculate an optimal solution of jurisdictional allocations. The system of equations would require too much information, information that is inherently dispersed throughout the polity. While admittedly we have seen how citizen mobility and differential taxes can act as a price-like mechanism in a territorially decentralised system of jurisdictions, which might suggest an information signalling role, we have also seen how there are inherent limitations to this process in comparison to non-territorial governance. A crucial condition for economic calculation is the existence of genuine entrepreneurship and market rivalry; and this condition is lacking when the bundledness and territoriality of the polity has been predetermined by a jurisdictional planner.

And even supposing informational assumptions most favourable to such a calculation (to echo Pareto, 'an absurd hypothesis') there would be little practical possibility of solving the problem due to the computational complexity of the task. This requires the planner to map the individual preferences of citizens over location and the numerous policy areas into a collective plan for how a geographic space will be partitioned into jurisdictions (i.e. territoriality) and how policy authority will be allocated among political units (i.e. bundledness). Consider that a given jurisdictional design can be classified as a configuration along three dimensions: (1) the extent of territorial decentralisation; $;^{50}$ (2) the extent of non-territorial decentralisation; ${ }^{51}$ and (3) the extent of bundling. ${ }^{52}$ The alternatives facing the planner have a combinatorial structure: each is characterised by a tuple of variables ranging over a finite domain, and as a result there are exponentially many possible allocations of authority among political units. The space of possible jurisdictional designs explodes in size as the number of potential territorial and non-territorial units, and number of unbundleable functions of governance, increases. ${ }^{53}$ 
Vincent Ostrom presaged 'the great multitudes of operational choices that become available when people can relate to one another through diverse institutional arrangements'. ${ }^{54}$ The standard approach in jurisdictional planning does not take the computational limitations induced by the combinatorial nature of the problem into account. Moreover, a plan that is ignorant of the multitudinous space of possibilities is likely to be to the detriment of citizen-choosers. If we were to proceed from a true appreciation of the overwhelming size and complexity of the jurisdictional design space, we would have profoundly less optimism in our ability to rationally construct an optimal architecture of governance. As James M. Buchanan and Viktor Vanberg argued, we need 'conditions for learning and adaptation at all levels at which we engage in problem solving, including the level at which we choose the constitutional framework for all other efforts' ${ }^{55}$ This is an invocation for a framework that is capable of generating experimentation and institutional diversity from within; that is, for non-territorial unbundling and political entrepreneurship. ${ }^{56}$

Moreover, we should recognise that information problems of this ilk are pervasive in all other marketplaces too, not only in the unbundled governance system envisaged here. The larger private economy does not comprise every possible combination of every good; firms offer products that are conjectured (or have been discovered) to be popular bundles of attributes, niche providers offer unique bundles, and specialist firms focus on singleattribute offerings. The genius of the competitive, decentralised market order is that it provokes persistent conjecture and refutation of market hypotheses through parallel experimentation, consumer sovereignty (i.e. mobility), and the ability to freely bundle product attributes as necessary (i.e. contestability, entry and exit).

We should expect a similar process to unfold in an unbundleable system of governance - perhaps counter-intuitively, we should expect bundling as the analogous response to information problems and the cognitive burden placed on citizens. ${ }^{57} \mathrm{~A}$ range of popular governance bundles might be offered (by individual public enterprises and consortiums) with popular single-element items available in the market for governance as well. There might also be the option of self-managing collective goods and services - consider them subscriptions - although it is unlikely that a large number of people would decide to undertake this, due to the inherent complexity of the task. While it is difficult to speculate on the prevailing structure following unbundling, the upshot is that simultaneous offerings and parallel governance promotes learning about which policy bundles are preferable to consumers and the appropriate way to produce and provide such services. 
Finally, another way consumers cope with decision burden in situations that are cognitively complex is to seek heuristics or appoint an agent with relevant expertise. In the current democratic system citizens vote for political parties on the dual basis of the bundle of policies they proffer and to appoint politicians as agents. In fact, there is an argument to be made that due to the 'rational ignorance' of voters, the appointment of politicians as agents is the primary function of an election. When, however, the functions of government are unbundled and citizens are able to individually curate a portion of their bundle of collective goods and institutions, elections may cease to be the dominant method by which the political-institutional environment adapts and changes. There is thus a motive for citizens to appoint an agent by contract, whether formal or tacit, and a new class of public enterprise dedicated to advising citizen-choosers might emerge. To be sure, political consultants, advocacy groups and think tanks already exist but they would potentially play a much more instrumental role in an unbundled political system, as complexity-reducing agents. The role of the political party would change markedly as well; at once rebundlers or consortiums of public enterprises and also highly visible, public enterprise advocates.

\section{NON-TERRITORIAL UNBUNDLING AS DISCOVERY}

The spectrum of ideas discussed in this chapter can be subsumed under the concept of 'non-territorial unbundling'. Much as the unbundled state defies prestatement, such a system could be described as a quasi-market public service industry of self-governing public enterprises, potentially multi-organisational and multifunctional, but with overlap and fragmentation, centralisation and decentralisation, subject to diverse economies of scale and with dissociation of production, provision and consumption. Gordon Tullock described such a system as 'a vast collection of governmental units, each of these governmental units being to some respect of a different geographical coverage than the others and each one dealing with a separate activity'. ${ }^{58}$ In Vincent Ostrom's terminology this is a 'highly federalised' system, ${ }^{59}$ although not necessarily territorially, as non-territorial collective good provision is likely to be preferable where possible.

What remains is the question of just which functions of governance are unbundleable, and which are necessarily linked to territory. And what's more, what governance functions can or should be performed by different levels of government. For the most part, it should be left to political entrepreneurs to experiment with provision of certain hitherto-conceived government goods and services. The central government might assist in the 
processes of discovering which functions are unbundleable by opening up niches for entrepreneurs to experiment in, monitoring results, and deciding if and when to scale up or terminate unbundled provision of the governance function. Of course, ultimately there will also be a political dimension to this, and it will be dependent on prevailing governments' (ideological) views on what functions of government are deemed acceptable for unbundling and what must remain centralised or within the bounds of the state.

It should also be stressed that non-territorial unbundling is not simply a ploy to rid ourselves altogether of the state, but rather an attempt to rid ourselves of a particular state: monopolistic, general-purpose, and territorially sovereign. Moreover, unbundling is more than just a process of 'decentring' the state; it involves a wide-ranging shift from government to governance, following from a recognition that a given collective good may be supplied, or a publicly necessary service performed, by a variety of bodies. These public enterprises may indeed resemble government departments, or fiscal clubs, communes, or companies; and ownership may reside in the state, a commons or, indeed, private enterprise. To echo Errico Malatesta: 'Probably all possible forms of ownership, use of the means of production and all forms of distribution will be experimented with simultaneously, in the same or other locations, and they will be merged together and adapted in various ways until practical experience identifies the best form or forms. ${ }^{90}$ But importantly, ownership and governance models that reflect community standards will proliferate in a social order where individuals choose for themselves the kinds of associations, communities and institutions they wish to be connected to.

In some respects, the non-territorial unbundling of the state is already underway: technological developments - especially in areas such as information, communication and encryption technologies - are shifting the balance away from purely territorial governance to more decentralised, non-territorial political forms. Such trends undermine the generalpurpose, territorial nation-state by opening up new governance structures and possibilities. Technological and economic advances have reduced the optimum scale of production in a wide range of industries, which is undermining, albeit gradually, the logic of large-scale centralised organisation. Similarly, network technology has had a revolutionary effect on the transaction costs of traditional economic activity and organisation, facilitating the emergence of more effective decentralised collective action practices. It provides a platform for new, non-territorial mechanisms of collective action for potentially widely dispersed communities, and the capability of virtual communities to provide multiple, non-territorial niches is ever-increasing. The upshot is that similar developments are driving this trend in many traditionally conceived functions of government, which is 
underwriting the rationale for small-scale, non-territorially decentralised, and functionally specialised modes of governance. The cumulative effect is that a rapidly increasing share of the functions previously carried out by the state could soon be effectively carried out by special-purpose public enterprises.

We could be on the verge of a non-territorial, unbundled future. But even so, it is important to recognise that even for societies at the forefront of social, political, and technological development, non-territorial unbundling represents an admittedly radical proposal and could only proceed in an incremental, piecemeal, and experimental way. While there may be difficulties with the pure version of this proposition, the benefits of non-territorial unbundling could be substantial. It is a system we can use to choose different sets of public goods and institutions that please the most number of people, rather than the same set of public goods and institutions that supposedly harm the least number of people.

Unbundling allows citizen-consumers to choose each element of government separately, rather than having to choose from a number of predefined, complete bundles without any substitution, and for a full term as a bloc. This overcomes the diminishing political preference satisfaction that is a consequence of ever-greater bundling of policy bundles in general-purpose governments (with commensurate implications for welfare). Non-territoriality provides the ability to subvert the trade-off between agglomerative efficiencies and political choice efficiencies that prevails when citizens sort themselves over a geographic space populated by territorial jurisdictions. It also spurs beneficial inter-jurisdictional competition without having to rely on citizen mobility, which places limits on government oversupply and over-taxation, 'taming Leviathan'. Parallel governance promotes parallel experimentation and learning about citizen preferences and policy alternatives, eliciting a quasi-Hayekian discovery process. Just as territorially decentralised policy experimentation is conceptualised as 'laboratory federalism' we can also describe the theory of the discovery process of non-territorial unbundling as 'laboratory panarchism'.

Non-territorial unbundling recognises the heterogeneity of political preferences over collective goods and institutions and the diversity of the population. Rather than a meddlesome constraint to political consensus, as in majoritarian democracy, unbundled governance is a pluralistic approach that embraces such diversity, with the view that the satisfaction of heterogeneous preferences is a necessary condition for any considered system of governance. Such an approach heeds Acton's warning of democracy as a 'tyranny of the majority'; provides a mechanism for responding to Churchill's claim that no other better form of governance than 
majoritarian democracy has yet been tried; and takes seriously Mencken's idea that people know what they want, and deserve to get it good and hard.

Moreover, this approach need not even assume people know the outcomes they desire, or that the proper assemblage of political authority and mode of governance is even a priori knowable. Rather, it provides a framework for experimentation and learning about policy alternatives and their consequences. While decentralisation is key, we need not presuppose decentralised governance and institutional forms will always be the outcome. This is a framework in which the assignment of powers can be discovered, and continually rediscovered, not assumed a priori-a framework for an unbundled state.

\section{NOTES}

1. Widely attributed to Franklin, although not found in any of his known writings.

2. 'The pervading evil of democracy is the tyranny of the majority, or rather of that party, not always the majority, that succeeds, by force or fraud, in carrying elections' (Acton 1877: 98).

3. A speech in the House of Commons on 11 November 1947: 'Many forms of Government have been tried and will be tried in this world of sin and woe. No one pretends that democracy is perfect or all-wise. Indeed, it has been said that democracy is the worst form of government except all those other forms that have been tried from time to time.' The second comment is also widely attributed to Churchill, but with no verified record or citation.

4. Mencken (1916: 19).

5. There are many paradoxes and problems of majoritarian voting: see Condorcet (1785); Hotelling (1929); Black (1948); Arrow (1950); Tullock (1959); Buchanan \& Tullock (1962); Gibbard (1973); Satterthwaite (1975). Boettke \& Leeson (2002), Caplan (2011), and DeCanio (2014) provide more recent contributions.

6. Concentrated market power (e.g. monopoly or oligopoly) inhibits allocative efficiency, which in the context of governance, is equivalent to the monocentric, majoritariandemocratic model. In this sense, a 'market for governance' can be described as 'allocatively efficient'.

7. Much of this literature is centred about discussion of the merits of polycentric governance (Tiebout 1956; Ostrom, Tiebout \& Warren 1961; McGinnis 1999a, 1999b; Kurrild-Klitgaard 2010; E. Ostrom 2010; Andersson 2012), club theory (Buchanan 1965; Sandler \& Tschirhart 1980, 1997; Casella \& Frey 1992; Leeson 2011, Sandler 2013), federalism (Hayek 1939; Tullock 1969; V. Ostrom 1973, 1976), and secession (Buchanan \& Faith 1987; Lowenberg \& Yu 1992; Kurrild-Klitgaard 2002).

8. This line of argument is best elucidated by Schleicher (2010) who calls attention to the conflict between 'sorting' and 'agglomerative' efficiencies, but only goes so far as to suggest that territorially bound government must balance this trade-off. Non-territorial governing units are bound by no such trade-off, as will be discussed later.

9. See, for instance, Buchanan (1975a) and Buchanan, Tollison \& Tullock (1980) on the distinction between 'protective', 'productive', and 'redistributive' politics; Krueger (1974) on the rent-seeking society; and Olson $(1965,1982)$ on collective action and the pernicious effect of distributional coalitions. When a particular set of political preferences is privileged at the expense of others, the redistributive consequences are akin to those outlined above. 
10. See e.g. Hotelling (1929) and Black (1948). See also Romer \& Rosenthal (1979) and Milanovic (2000) for empirical analyses.

11. Economists have examined product bundling, tie-in sales, and block-booking since the 1960s; see e.g. Stigler (1963); Adams \& Yellen (1973); Guiltinan (1987); Bakos \& Brynjolfsson (2000). The rationale for product bundling is to induce customers who would purchase only one or few products to also buy unwanted or less valued products, thereby extracting greater profits and surplus from consumers than if they were marketed separately (i.e. surplus transfer from highly valued to less valued products).

12. Bundling can violate the conditions for distributive and allocative efficiency, depending on the particulars of the market setting, e.g. scale and scope economies in production, complementarity or substitutability in consumption, budget constraints. In oligopolistic and monopolistic settings - such as with the provision of political goods by a central government or by few territorially decentralised governments-bundling can be seen as an unfair use of market power if it prevents new entry of rival producers and limits choices available to consumers.

13. See e.g. Tiebout (1956); Ostrom, Tiebout \& Warren (1961); Buchanan (1965); Tullock (1969); V. Ostrom (1973, 1976); Buchanan \& Faith (1987).

14. See Bräutigam \& Xiaoyang (2011), Wang (2013), and Moberg (2015) on special economic zones; Romer (2010a, 2010b) on charter cities; Beito, Gordon \& Tabarrok (2002) and Rajagopalan \& Tabarrok (2014) on private cities; and Friedman \& Taylor (2012) on seasteading.

15. Megginson \& Netter (2001) provide a survey of empirical studies on privatisation, while seminal contributions to the theory of private governance include Friedman (1973), Benson (1990), Dixit (2007), Stringham (2007, 2015), and Beito, Gordon \& Tabarrok (2002).

16. Hooghe \& Marks $(2001,2003)$ are exemplars of multi-level governance theory.

17. Casella \& Frey (1992), Frey \& Eichenberger (1999), and Frey (2001) represent the theory of functional, overlapping and competing jurisdictions.

18. Landauer (1978), Benda et al. (1988), Bey (1991), Newman (2010, 2011), and Lagos, Coopman \& Tomhave (2014) explore the possibility of creating institutions to parallel incumbent states.

19. Lijphart $(1985,2004)$ and O'Leary, Lustick, \& Callaghy (2001) discuss consociation and power sharing on territorial and non-territorial bases.

20. The theory and practice of non-territorial autonomy and national-cultural autonomy is evaluated by Coakley (1994), Nimni (1999, 2004, 2007, 2015), De Villiers (2012), and Nimni, Osipov \& Smith (2013).

21. The Ottoman millet system is investigated by Braude \& Lewis (1982), Kuran (2004), and Barkey (2005, 2008), while Friedrichs (2001), Slaughter (1997), Rapley (2006), Kayaoglu (2010), and MacKenzie (2014) study extraterritoriality past and future.

22. Seminal contributions to the political philosophy of panarchism include Puydt (2015 [1860]) and Nettlau (2015 [1909]), while Zube (2015 [1986]), Long (2015 [1993]), Borders (2009), and Tucker (2015b) have recently addressed the subject.

23. Nozick's (1974) reinvents the theory of clubs in a non-territorial context, with Bader \& Meadowcroft (2011) recently compiling a companion text.

24. Further works on non-territorial self-governance include Schlick (1952), Elkins (1992, 1995, 1997), Schleichert (2003), Kukathas (2003, 2008), and Weinersmith (2014).

25. Tiebout (1956: 422).

26. Hayek (1948) and Kirzner (1997).

27. For application of the competition as discovery ethos to institutional competition, see Vihanto (1992), Vanberg \& Kerber (1994), Kerber (2006), Stringham \& Zywicki (2011).

28. On the importance of parallel experimentation see Thomke, Von Hippel \& Franke (1998), Ellerman $(2004,2014)$, and Saam \& Kerber (2013).

29. While it seems forthright to suggest that territorially decentralised, polycentric systems (known as 'laboratory federalism') outperform monocentric systems from the 'evolution of knowledge' and dynamic efficiency perspectives, this also raises a question: Isn't 
parallel experimentation more accurately reflected in a system of non-territorially decentralised policy laboratories? Thus one might neologise the term 'laboratory panarchism' for non-territorial unbundling; and perform 'comparative social epistemics' (cf. comparative institutional analysis) as to whether territorial or non-territorial policy laboratories cultivate superior conditions for parallel experimentation and institutional knowledge discovery.

30. See Schleicher (2010) for a fuller elaboration of the trade-off between agglomerative efficiency and sorting efficiency.

31. This contention comes from Roderick Long's (2015 [1993]) description of virtual cantons. It is also reminiscent of the model of national-cultural autonomy proposed by Austrian Social Democrats Karl Renner and Otto Bauer at the beginning of the twentieth century to accommodate considerable ethno-national diversity in the AustroHungarian Empire (see Nimni 1999, 2004); and the millet system of governance from the multicultural and multi-religious Ottoman Empire (see Barkey 2005, 2008).

32. Patri Friedman makes this very point in a post on Let A Thousand Nations Bloom blog and in his work on competitive governance and seasteading, e.g. Friedman \& Taylor (2012).

33. Rozeff (2010: 1).

34. Buchanan \& Goetz (1972: 27).

35. The analogy to television comes from a post by Arnold Kling on EconLog for the Library of Economics and Liberty: 'Many people resent the way that cable TV companies bundle their packages of services. I have that same resentment over government bundling.' The phrase 'unbundling government' originates from either Kling's blogging or the aforementioned Let A Thousand Nations Bloom blog (both c.2009-10).

36. See Buchanan \& Tullock (1962) for discussion of the legitimacy and costs of the conceptual unanimity rule (and alternative rules) in political decision-making. The economic theory of non-territorial unbundling could be incorporated into analyses of this kind.

37. See Hooghe \& Marks (2001, 2003), Frey \& Eichenberger (1999), and Frey (2001) for a fuller elaboration of these arguments.

38. Olson (1969: 483).

39. Ibid.

40. See Tullock (1969) for an analytical approach to internalising inter-jurisdictional spillovers.

41. There is a deeper point to be made here about comparing a 'rationally constructed' jurisdictional design that is presumed 'optimal' (minimising inter-jurisdictional spillovers) and one that emerges from the process of political entrepreneurship and citizen choice. Such an order can only emerge from individual interaction and any comparison is epistemologically and ontologically suspect. This is the jurisdictional analogue to the argument in Buchanan (1982) about the logical impossibility of replicating an emergent market order.

42. See Potts (2009) for an evolutionary perspective on the problem of too much static efficiency.

43. Ellerman (2014: 259).

44. Buchanan and Tullock (1962), Buchanan (2003b).

45. Boettke \& Leeson (2004), Leeson \& Subrick (2006), Pennington (2011).

46. The socialist calculation debate was carried out between Austrian economists Ludwig von Mises and Friedrich Hayek, and neoclassical and Marxist economists Oskar Lange, Abba Lerner and Fred Taylor. The position of Mises and Hayek was to highlight the economic calculation problem: economic planning was no substitute for market allocation of resources due to the absence of the price mechanism. That is, 'rational economic activity is impossible in a socialist commonwealth' (Mises 1990: 33) because the information provided by market prices is lacking in a system of bureaucratic or technocratic allocation. See Mises (1920, 1990), and Hayek (1935).

47. Pareto (1906: 171): 'Let us make the hypothesis most favorable to such a calculation; 
assume that we have overcome all the difficulties in the way of acquiring knowledge of the data of the problem, and that we know the ophelimities of all the goods of each individual, all the particulars pertaining to the production of the goods, etc. This is already an absurd hypothesis, and yet it still does not provide us with the practical possibility of solving the problem. We have seen that in the case of 100 individuals and 700 goods there would be 70,699 conditions (in reality a great number of particular details, which we have disregarded so far, would increase this number further); then we would have to solve a system of 70,699 equations. As a practical matter, that is beyond the power of algebraic analysis, and it would be still further beyond it if we considered the fabulous number of equations which a population of forty million individuals, and several thousand goods would entail. ...In other words, if all these equations were actually known, the only means of solving them would be to observe the actual solution which the market gives.'

48. Ibid. Note that this is different to the argument made by Hayek (1945) that price signals are essential for coordinating tacit and dispersed information. Pareto assumes away the knowledge problem - while acknowledging the absurdity of such a move - and instead extends his argument to the computational complexity of the mathematical optimisation problem with such myriad objectives and constraints. While computational power has increased dramatically, for the complex economies and heterogeneous polities of today such calculations still remain outside the realm of possibility (Nove 1983; Beinhocker 2007).

49. Pareto (1906: 171). Buchanan (1982 and endnote 41 above) came to a similar conclusion about the logical impossibility of comparison between bureaucratic-technocratic allocation that is presumed 'optimal' and the market order. Pareto's is about the practical impossibility of replicating an optimising market allocation.

50. Defined as the number of territorial political units the geographic space is partitioned into.

51. The number of non-territorial political units layered within the geographic space.

52. The extent to which the above allocations of political authority to political units correlate across the various functions of governance.

53. For one function of governance (hence no unbundling) and up to two territorial political units or up to two non-territorial political units and any combination thereof, there are only seven possible designs. Extending this setting to two functions of governance (and hence now permitting unbundling) sees the number of possible designs expand to 147. For one function of governance and up to three territorial political units or up to three non-territorial political units, there are 86 possible designs. Now, extending this to two functions and permitting unbundling yields over a thousand possible jurisdictional designs. In the same way that Pareto noted the computational complexity of calculations under even the most favourable of conditions, one should pause to reflect on the complex combinatorics of the jurisdictional design space with similarly favourable dimensions. Perhaps 20 functions of government, up to 20 territorial political units, and up to 20 non-territorial units (which seems prima facie to be a very restrained simplification of reality), would yield innumerable combinations of possible jurisdictional designs. This exponentially increases the subsequent optimisation problem-allocating 'a population of forty million individuals' among territorial and non-territorial political units for the multitudes of possible jurisdictional designs would certainly 'exceed the capacity of algebraic analysis'.

54. V. Ostrom (1988: 184).

55. Buchanan \& Vanberg (2002: 128-9).

56. See also Potts (1999; 2000), Caceres (2014), Felin et al. (2014), and Koppl et al. (2014) on the complexity of economic space and the roles of entrepreneurship and competitive governance in rendering the complexity intelligible.

57. See Potts (2012) on novelty-bundling markets as a solution to the problem of complexity and decision burden in choice domains that are information-intensive, uncertain and difficult for consumers. 
58. Tullock (1969: 25).

59. V. Ostrom (1973: 205): 'I prefer to characterize a "highly federalized" political system as one which has a rich structure of overlapping jurisdictions with substantial autonomy among jurisdictions.'

60. Malatesta (1995 [1929]: 114). 